\title{
The B190 Computer Controlled Radiation Monitoring and Safety Interlock System
}

\author{
M.L. Roberts \\ W.F. Fields \\ D.E. Gittins \\ D.L. Espinosa
}

August 1998

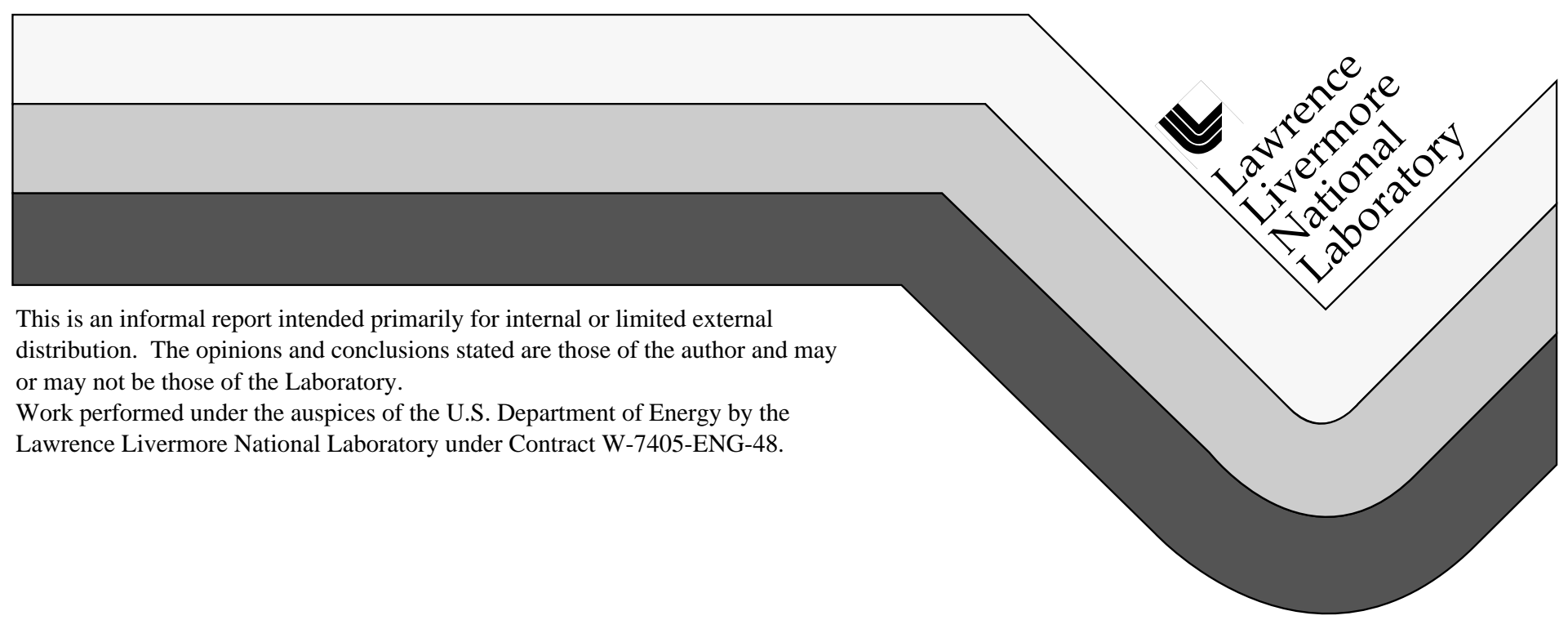




\section{DISCLAIMER}

This document was prepared as an account of work sponsored by an agency of the United States Government. Neither the United States Government nor the University of California nor any of their employees, makes any warranty, express or implied, or assumes any legal liability or responsibility for the accuracy, completeness, or usefulness of any information, apparatus, product, or process disclosed, or represents that its use would not infringe privately owned rights. Reference herein to any specific commercial product, process, or service by trade name, trademark, manufacturer, or otherwise, does not necessarily constitute or imply its endorsement, recommendation, or favoring by the United States Government or the University of California. The views and opinions of authors expressed herein do not necessarily state or reflect those of the United States Government or the University of California, and shall not be used for advertising or product endorsement purposes.

This report has been reproduced directly from the best available copy.

Available to DOE and DOE contractors from the Office of Scientific and Technical Information P.O. Box 62, Oak Ridge, TN 37831

Prices available from (423) 576-8401

Available to the public from the National Technical Information Service

U.S. Department of Commerce 5285 Port Royal Rd. Springfield, VA 22161 


\title{
The B190 Computer Controlled Radiation Monitoring and Safety Interlock System
}

\author{
W.F. Fields, D.E. Gittins, D.L. Espinosa, and M.L. Roberts \\ Center for Accelerator Mass Spectrometry \\ Lawrence Livermore National Laboratory \\ Livermore, CA 94551 USA
}

August, 1998 



\title{
The B190 Computer Controlled Radiation Monitoring and Safety Interlock System
}

\author{
W.F. Fields, D.E. Gittins, D.L. Espinosa, and M.L. Roberts \\ Center for Accelerator Mass Spectrometry \\ Lawrence Livermore National Laboratory \\ Livermore, CA 94551 USA
}

\begin{abstract}
The Center for Accelerator Mass Spectrometry (CAMS) in the Earth and Environmental Sciences Directorate at Lawrence Livermore National Laboratory (LLNL) operates two accelerators and is in the process of installing two new additional accelerators in support of a variety of basic and applied measurement programs ${ }^{[1,2,3,4]}$. To monitor the radiation environment in the facility in which these accelerators are located and to terminate accelerator operations if predetermined radiation levels are exceeded, an updated computer controlled radiation monitoring system has been installed. This new system also monitors various machine safety interlocks and again terminates accelerator operations if machine interlocks are broken. This new system replaces an older system that was originally installed in $1988^{[5]}$. This paper describes the updated B190 computer controlled radiation monitoring and safety interlock system.
\end{abstract}




\section{Facility Description}

The Center for Accelerator Mass Spectrometry (CAMS) operates several accelerators in LLNL's Building 190 (B190). B190 is a metal building of approximately 7000 square feet and contains a 10 MV High Voltage Engineering Corporation Model FN Tandem Van de Graaff accelerator and a 1.7 MV National Electrostatics Engineering Corporation Model 5SDH-2 Tandem Van de Graaff accelerator.

Within the next year, a 1.0 MV National Electrostatics Engineering Corporation Model 3SDH-1 Tandem Van de Graaff accelerator and an AccSys Technology, Incorporated Radio Frequency Quadrupole accelerator that can accelerate ${ }^{3} \mathrm{H}$ ions to $1.5 \mathrm{MeV}$ will be added to B190. A floor plan of B190 is shown in Figure 1.

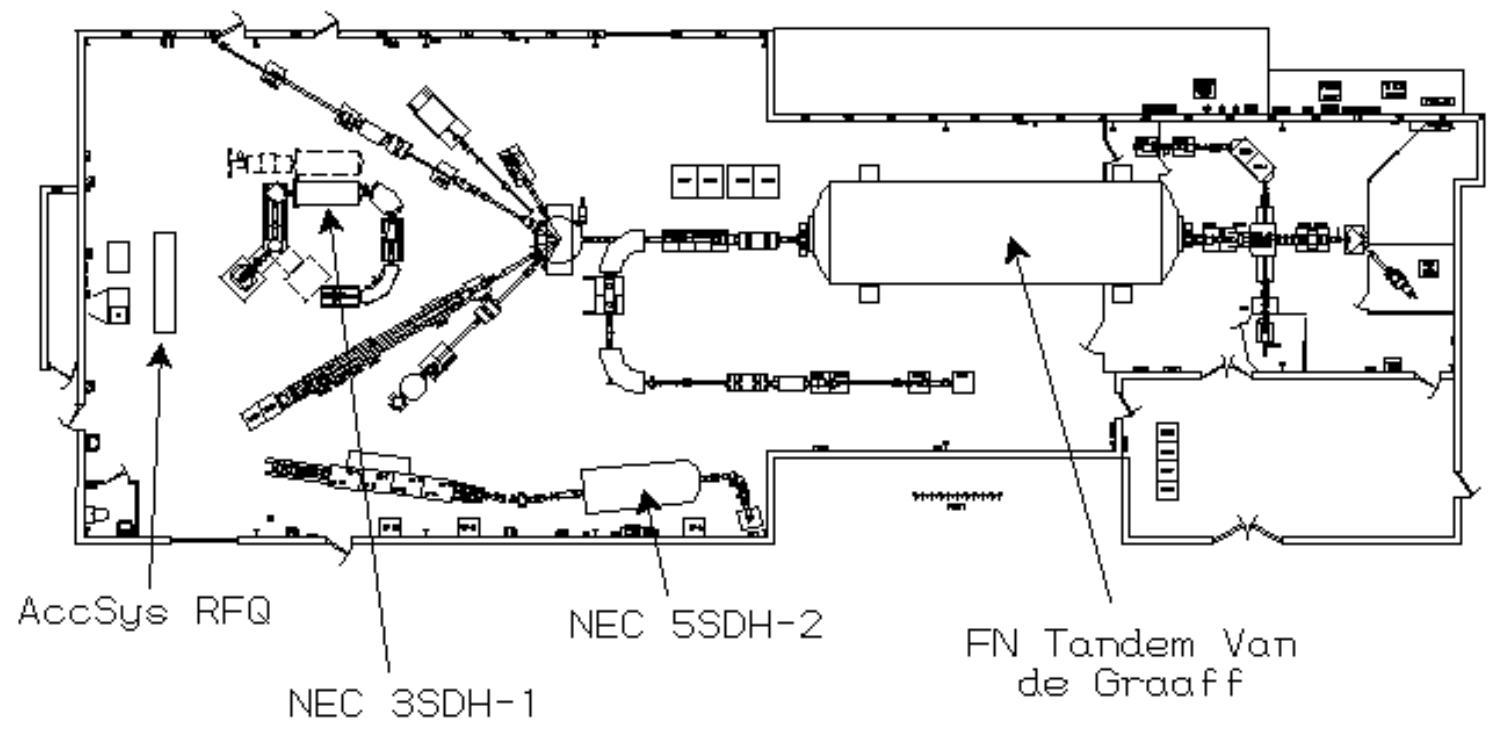

Figure 1. Floor plan of Building 190

Original design goals for B190 were inexpensive construction, inexpensive operation, high beam quality at a large number of experimental stations, and versatility in adapting to new experimental needs. To accomplish these goals, design decisions were made to place the original FN tandem Van de Graaff accelerator (and hence the other accelerators) in an unshielded structure and to rely on computer control systems for both radiological protection and highly reproducible and well-characterized accelerator operation. This paper addresses the computer controlled radiation monitoring and safety interlock system.

\section{Accelerators}

The Model FN Tandem Van de Graaff accelerator is used primarily for Accelerator Mass Spectrometry (AMS). AMS is an extremely sensitive technique for the measurement of long-lived radionuclides. The FN was manufactured by the High Voltage Engineering Corporation in 1963 as the University of Washington injector tandem. The FN was moved to LLNL in 1987 and B190 was constructed around the accelerator. At LLNL, the FN was upgraded from a traditional rubber charging belt to a metal and nylon pellet system and the original accelerator tubes were upgraded to a type whose 
electric field design is optimized to suppress the generation and acceleration of secondary electrons. Maximum terminal voltage of the FN is near $10 \mathrm{MV}$. For AMS, ion beams are provided from one of two nearly identical cesium type sputter sources. Table 1 contains a partial list of ions, ion currents, and beam energies run on the FN accelerator.

\section{Table 1}

Partial list of ions, ion currents, terminal voltage, and beam energies run on the Model FN Tandem Van de Graaff accelerator

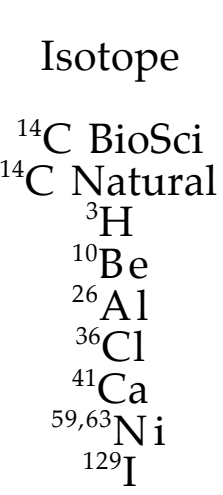

$$
\begin{gathered}
\text { Stable Ion } \\
\text { Current } \\
150 \mathrm{~mA}^{12} \mathrm{C}^{-} \\
200 \mathrm{~mA}^{12} \mathrm{C}^{-} \\
15 \mathrm{~mA}^{1} \mathrm{H}^{-} \\
4 \mathrm{~mA}^{9} \mathrm{BeO}^{-} \\
1 \mathrm{~mA}^{27} \mathrm{Al}^{-} \\
20-40 \mathrm{~mA}^{37} \mathrm{Cl}^{-} \\
500 \mathrm{nA}^{40} \mathrm{CaF}^{3-} \\
5 \mathrm{~mA}^{58} \mathrm{Ni}^{-} \\
25 \mathrm{~mA}^{129} \mathrm{I}^{-}
\end{gathered}
$$$$
\text { Terminal }
$$$$
\text { Voltage (MV) }
$$

Beam
Energy (

32.5
32.5
6.0
23.0
56.0
66.4
75.8
99.0
42.0

66.4

75.8

42.0

The 1.7 MV National Electrostatics Engineering Corporation Model 5SDH-2 Tandem Van de Graaff accelerator is primarily utilized by CAMS's Ion Micro-Analysis Group (IMAG). The IMAG group uses the techniques of Proton Induced X-ray Emission and Scanning Transmission Ion microscopy to generate element distribution maps and projected densities of samples to sub-micron spatial resolution. The 5SDH-2 was installed in B190 in 1996. The $5 \mathrm{SDH}-2$ has a maximum terminal voltage of $1.7 \mathrm{MV}$ but is normally run at 1.5 MV to generate $3.0 \mathrm{MeV}$ protons. Beam currents are on the order of $10 \mathrm{~mA}$. The ion source for the 5SDH-2 is a Direct Extraction Negative Ion Source.

Within the next year, two new accelerators will be added to B190. The first accelerator to be added will be an AccSys Technology, Incorporated, Radio Frequency Quadrupole (RFQ) accelerator. The RFQ will be part of an AMS system that will be used in the biological tracing of ${ }^{3} \mathrm{H}$. In normal operation, ${ }^{1} \mathrm{H}$ ions will accelerated to $0.5 \mathrm{MeV},{ }^{2} \mathrm{H}$ ions will accelerated to $1.0 \mathrm{MeV}$, and ${ }^{3} \mathrm{H}$ ions will accelerated to $1.5 \mathrm{MeV}$. Injected ions will come from a cesium type sputter source. ${ }^{1} \mathrm{H}$ ion currents are anticipated to be around $15 \mathrm{~mA}$.

The second accelerator to be added to B190 in the next year will be a 1.0 MV National Electrostatics Engineering Corporation Model 3SDH-1 Tandem Van de Graaff accelerator. The 3SDH-1 will be part of an AMS system that will be used in the biological tracing of ${ }^{14} \mathrm{C}$. In normal operation, carbon ions will be accelerated to be between 2.0 and $3.0 \mathrm{MeV}$. Injected ions will again come from a cesium type sputter source. ${ }^{12} \mathrm{C}^{-}$ion currents are anticipated to be around $150 \mathrm{~mA}$.

\section{Radiation Monitoring System}

LLNL's radiation shielding design criterion for personnel radiation exposure is to ensure that the maximum annual personnel radiation dose 
does not exceed $500 \mathrm{mR}$. This design policy can be implemented by any combination of controlling personnel exposure time, using physical shielding, and excluding personnel from radiation zones.

Most experiments in B190 involve the acceleration of ions under conditions that result in radiation levels below $1 \mathrm{mR} / \mathrm{hr}$ in occupied areas. Occasionally, however, experimental conditions produce radiation levels of up to $100 \mathrm{mR} / \mathrm{hr}$. In order to keep B190 an open and accessible area, a safe radiation environment is provided by local shielding around slits and beam dumps and a radiation monitoring system. The radiation monitoring system described in this document continuously monitors the B190 work environment and automatically suspends accelerator operations if preset radiation levels are exceeded.

The radiation monitoring system consists of both computer-monitored and stand-alone radiation detectors. The computer-monitored part of the system comprises both photon and neutron detectors. Separate from the computer-monitored part of the system are three stand-alone detectors. These three detectors detect only photons and serve as 'back-up' to the computer-monitored part of the system. The three detectors are distributed throughout B190 with one located in the ion source area, the second at the mid-plane of the FN tandem accelerator, and the third at the forward-beam experimental area. The ion source detector turns on a rotating red light if the radiation dose rate exceeds $5 \mathrm{mR} / \mathrm{h}$ and shuts off the ion sources if the rate exceeds $100 \mathrm{mR} / \mathrm{h}$. The mid-plane and forward-beam experimental detectors turn on a rotating red light if the radiation dose rate exceeds $5 \mathrm{mR} / \mathrm{h}$ and automatically terminate accelerator operations if the rate exceeds $100 \mathrm{mR} / \mathrm{h}$.

Figure 2 shows the location of all radiation detectors in B190. Figure 2 also shows that B190 is divided into three radiation zones: Zone 1 is generally defined as the forward beam experimental area of B190, Zone 2 is the ion source and control room area for the FN tandem accelerator, while Zone 3 is the area outside of B190. Depending on the expected ionizing radiation level, Zone 1 can be classified as either an Open, Controlled or Exclusion area.

When Zone 1 is configured as a Open area, no accelerator operations are permitted. In the Open mode, access to B190 is permitted through all doors.

When Zone 1 is configured as a Controlled area, accelerator operations are automatically terminated if the instantaneous rate on any radiation detector exceeds $100 \mathrm{mR} / \mathrm{h}$ or the hourly integrated dose exceeds $1 \mathrm{mR}$. In the Open mode, access to B190 is permitted only through the two control room doors and the North and South roll-up doors (which open only from the inside).

When Zone 1 is configured as an Exclusion area, accelerator operations are automatically terminated if the integrated hourly radiation dose in Zone 2 or 3 exceeds $1 \mathrm{mR}$. In Exclusion mode, no personnel access to Zone 1 is permitted. Before Exclusion mode is implemented, a series of watchmen's stations must be activated in a prescribed manner and time to ensure that no personnel are present in the Exclusion area when accelerator operations begin. 


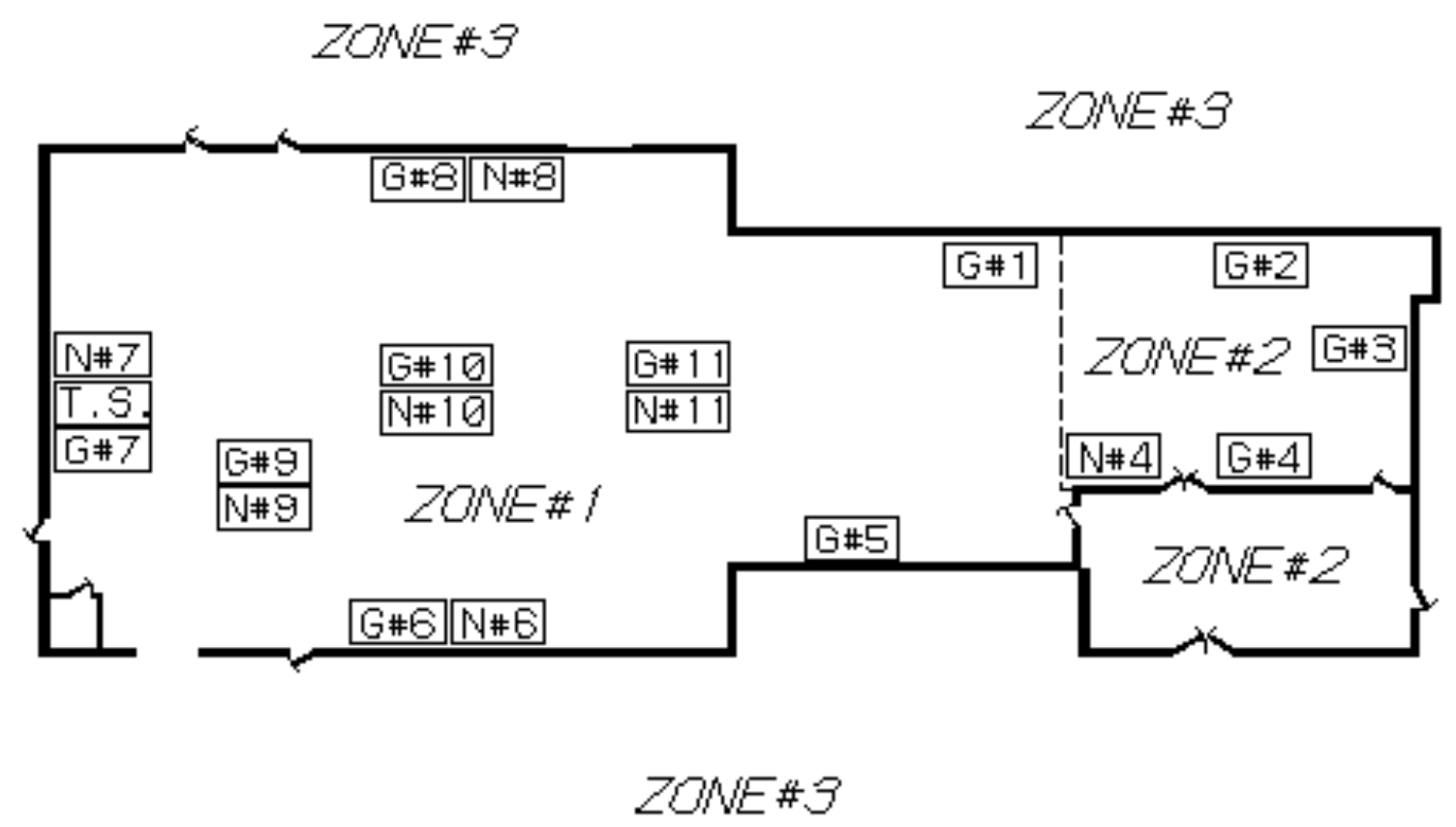

Figure 2. Location of radiation zones and detectors in B190.

\section{Safety Interlock System}

An interlock chain monitors all entry and exit to B190, including the basement and emergency exits. The status of access points is monitored using double, in-series microswitches. In addition to the door microswitches, run-safe boxes are located throughout B190. These boxes are serially connected with the interlock loop and must be sequentially activated when configuring Zone 1 as an Exclusion area. The run-safe boxes also indicate whether Zone 1 is configured as an Open, Controlled or Exclusion area. The interlock system signal is +24 volts direct current (VDC). If any microswitch is disabled (e.g., opening an interlocked door or gate or depressing a run-safe switch), accelerator operations are automatically terminated.

In addition to the 'personnel' interlocks, several 'machine' interlocks are part of the safety interlock system. Examples of 'machine' interlocks include the FN tandem accelerator tank pressure and FN accelerator tube pressures. If any of these 'machine' interlocks are disabled, accelerator operations are automatically terminated. The difference between 'personnel' interlocks and 'machine' interlocks are that 'machine' interlocks protect hardware while 'personnel' interlocks protect people. In general, 'machine' interlocks in B190 are not redundant (i.e., double in-series microswitches are not used for 'machine' interlocks).

\section{Hardware}

The computer for the radiation monitoring system and safety interlock system is a Power Macintosh 7200/90 located in the B190 control room. The computer provides dose rate, integrated dose, and interlock status to the accelerator operators. An overview of the radiation monitoring system and safety interlock system hardware is shown in Figure 3. Each hardware component is described in detail below. 


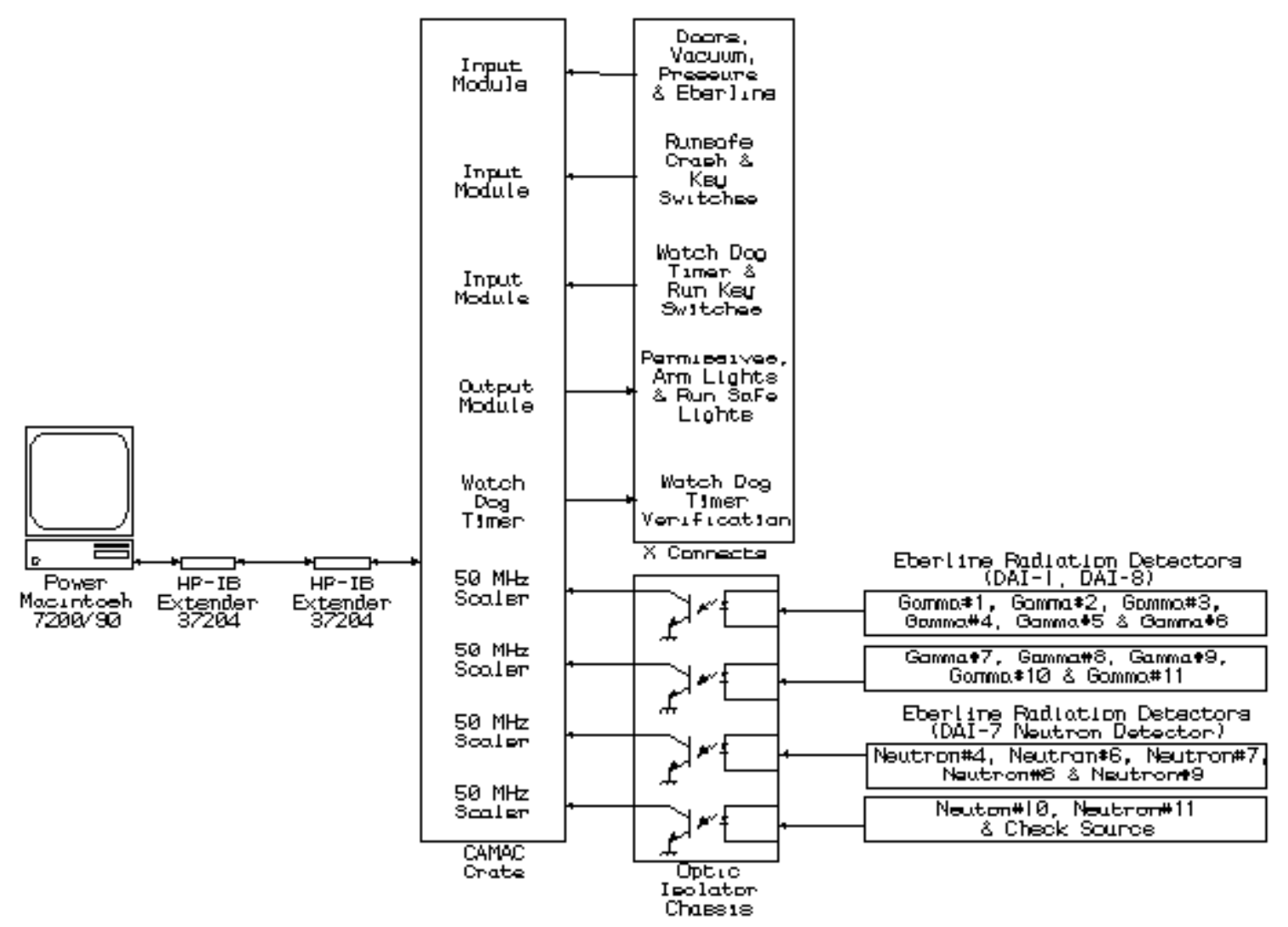

Figure 3. An overview of the Radiation Monitoring System and Safety Interlock System hardware.

Photon detectors for the radiation monitoring system consist of pressurized ionization chamber detectors and Geiger Mueller (GM) detectors. Neutron detectors for the radiation monitoring system are ${ }^{6} \mathrm{Li}$ solid-state detectors surrounded by a two-inch-thick polyethylene moderation jacket. Each detector assembly contains its own high-voltage power supply, charge-to-pulse converter (ionization chamber), low-voltage regulator, and line driver. The units are powered by +12 VDC at $85 \mathrm{~mA}$ and generate a nominal 3.4 VDC alternating polarity signal, whose frequency is proportional to the ionization chamber current, GM count rate, or neutron count rate as applicable. The Eberline Instrument Corporation, Santa Fe, New Mexico, manufactures the detector assemblies.

The photon and neutron detectors are connected to the radiation monitoring system by a four-wire cable bundle consisting of a low-voltage power-and-ground pair and a coaxial signal cable. Maximum-rated signal cable length is approximately $300 \mathrm{~m}$ with the 22 AWG wire used. Each detector continuously sends signals to an optical isolator chassis located in the radiation monitoring system instrument rack. The optical isolator chassis buffers the incoming detector signals for counting by one of four Kinetic Systems Model 3610 Hex Counter modules. Each counter module has 6 channels. The counter modules are sequentially polled approximately every 5 seconds, and the current dose rate and hourly integrated dose are calculated by the radiation monitoring system control computer. 
For the safety interlock system, the status of the key switches, crash buttons, doors, vacuum permissives, hard-wired Eberline radiation monitors, and the watch dog timer are monitored by three Kinetic Systems Model 3471 input modules. Each input module has 24 channels and is polled approximately 10 times per second. Output permissives to the various accelerators are provided by a Kinetic Systems Model 3072 output module. The output module also provides signals for the Run/Safe and arm lights. The module has 48 output channels and is updated on an as needed basis.

The scalar modules for the radiation monitoring system and the input/output modules for the safety interlock system are located in a CAMAC crate in the radiation monitoring and safety interlock system instrument rack located along the North wall of B190. The CAMAC crate is controlled by a Kinetic Systems Model 3988 GPIB crate controller connected to the Macintosh control computer via a HP-IB fiber optic extender.

To monitor for radiation monitoring system computer malfunctions (e.g., if the computer's central processing unit locks up), a Standard Engineering CAMAC crate watchdog timer continuously confirms proper computer operation. During each radiation monitor polling sequence, a +24 VDC signal pulse is transmitted to the timer. If the computer fails to provide this signal for more than 240 seconds, the watchdog timer automatically terminates accelerator operations. After the watchdog timer stops accelerator operations, the system must be manually restarted.

In addition to the watchdog timer, we have dedicated a detector for quality control of the detector power system and hardware. This detector continuously monitors an internal ${ }^{137} \mathrm{Cs}$ check source and automatically terminates accelerator operations if the signal falls below a specified value.

\section{Software}

The software for the radiation monitoring and safety interlock system is LabView 4.0. The software is not accessible to the accelerator operator or experimenters. Within LabView, each process is broken down in subsequent diagrams until all processes are addressed. System documentation includes all subsequent process documentation and a data dictionary, which describes all system variables.

As is shown in Figure 4, the radiation monitoring and safety interlock system computer program provides a graphical display of the B190 radiation levels and safety interlock status. The computer program also archives hourly radiation levels onto the computer hard disk. Archiving hourly radiation levels could prove useful should the need ever arise to 'reconstruct' the B190 radiation history. 

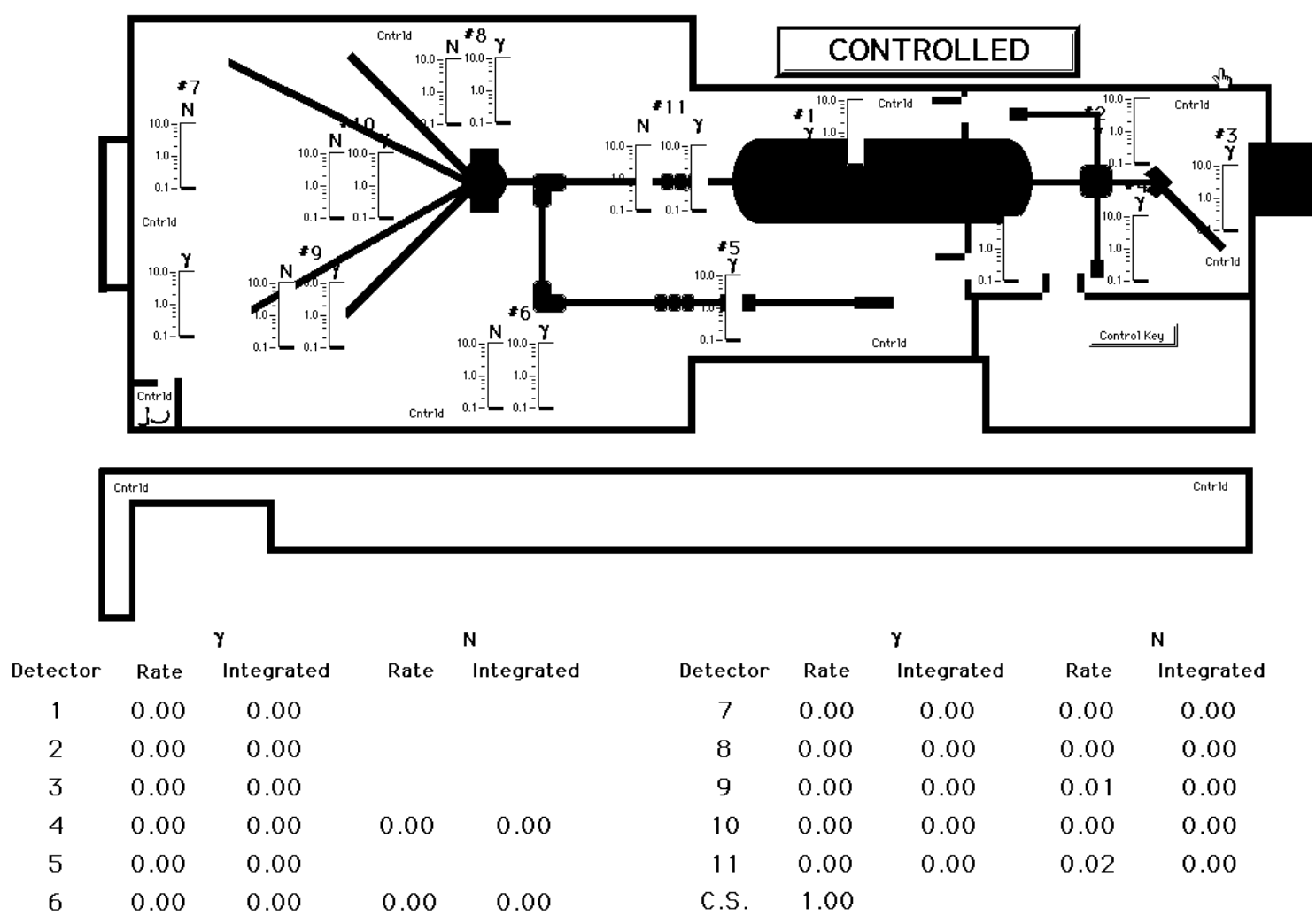

Figure 4. Representative display from the radiation monitoring and safety interlock system control computer.

\section{Discussion}

The new computer controlled radiation monitoring and safety interlock system has been installed for only two months. While two months is too short of a time to determine if the new system will have any problems, the old system ran for nearly ten years without any significant operating problems. As with the old system, radiation monitors will be calibrated every six months. On the old system, calibration constants [i.e., (pulse rate)/(R/h)] remained almost constant from year to year. Detector background levels were and are consistently of the order of $0.01 \mathrm{mR} / \mathrm{h}$.

In addition to providing a safe and documented radiation environment, the radiation monitoring system has been beneficial in keeping radiation exposure as low as reasonably possible. The display of real-time radiation levels and warnings provides accelerator operators a feedback loop for minimizing unnecessary radiation levels at slits, collimators, and other beam-line components.

The new radiation monitoring system will also be useful as a predictive design tool. Before operating the accelerator for experiments involving new accelerator operating parameters or experimental configurations, the old radiation monitoring system was used to scope out the radiation environment at $1 \%$ or less of the proposed accelerator operating scenario. The actual radiation measurements were then used to design local radiation shielding or administrative barriers as needed. The new radiation 
monitoring system will be used in the same manner.

With the old radiation monitoring system, accelerator operations were terminated automatically several times over the past few years. In most cases, accelerator operations were terminated because Zone 1 was configured as a Controlled area and the $1 \mathrm{mR}$ hourly integrated dose criterion was exceeded. In all cases, the termination was warranted.

All B190 operators, experimenters, and maintenance personnel wear thermoluminescent dosimeters. No B190 worker has ever been found to have a radiation dose measured above natural background level throughout the operating history of B190. However, two employees did receive a dose of approximately $10 \mathrm{mR}$ while refurbishing an accelerator magnet. They received this dose from magnet components that had been activated when the accelerator was operated as a cyclotron by previous owners.

\section{Summary}

An updated Radiation Monitoring and Safety Interlock System has been installed in the accelerator facility of the Center for Accelerator Mass Spectrometry (CAMS) in the Earth and Environmental Sciences Directorate at Lawrence Livermore National Laboratory. This system monitors the radiation environment in the accelerator facility and terminates accelerator operations if predetermined radiation levels are exceeded. In addition to radiation, this new system also monitors various machine safety interlocks and again terminates accelerator operations if machine interlocks are broken.

The computer-controlled radiation monitoring system has proven extremely useful for real-time monitoring of the radiation environment of our facility and maintaining personnel exposure as low as reasonably achievable. Key to the reliability of our computer-controlled system is a watch-dog timer to detect CPU failure and independent stand-alone radiation monitors.

\section{References}

[1] “LLNL/UC AMS Facility and Research Program," J.C. Davis, I.D. Proctor, J.R. Southon, M.W. Caffee, D.W. Heikkinen, M.L. Roberts, T.L. Moore, K.W. Turteltaub, D.E. Nelson, and J.S. Vogel, Nuclear Instruments and Methods in Physics Research B52 (1990) 269-272.

[2] "The Bioscience Nuclear Microscopy Program at LLNL," G.S. Bench, S.P.H.T. Freeman, M.L. Roberts, and E. Sideras-Haddad, Nuclear Instruments and Methods in Physics Research B130 (1997) 419-425.

[3] "Materials Analysis at the SNL/LLNL Nuclear Microprobe," D.H. Morse, A.J. Antolak, G.S. Bench, D.W. Heikkinen, M.L. Roberts, and E. Sideras-Haddad, Nuclear Instruments and Methods in Physics Research B130 (1997) 740-745.

[4] "The LLNL AMS Facility," M.L. Roberts, G.S. Bench, T.A. Brown, M.W. Caffee, R.C. Finkel, S.P.H.T. Freeman, L.J. Hainsworth, M. Kashgarian, J.E. McAninch, I.D. Proctor, J.R. Southon, and J.S. Vogel, Nuclear Instruments and Methods in Physics Research B123 (1997) 57-61. 
[5] "The LLNL Multiuser Tandem Laboratory Computer-Controlled Radiation Monitoring System," S.G. Homann, UCRL-ID-106308. 